NBER WORKING PAPER SERIES

\title{
EXCHANGE-RATE POLICY AFTER A DECADE OF "FLOATING"
}

William H. Branson

Working Paper No. 909

NATIONAL BUREAU OF ECONOMIC RESEARCH

1050 Massachusetts Avenue

Cambridge MA 02138

June 1982

This is a revision of a paper presented at the NBER Conference on Exchange Rates, January 25-29, 1982, Bellagio, Italy. Not for quotation; comments welcome. The research reported here is part of the NBER's research program in International Studies. Any opinions expressed are those of the author and not those of the National Bureau of Economic Research. 
NBER Working Paper $\$ 909$

June 1982

\section{Exchange-Rate Policy After a Decade of "Floating"}

\section{ABSTRACT}

This paper integrates exchange-rate policy into a model of exchangerate behavior, and examines the data econometrically to infer hypotheses about policy behavior in the 1970s. The model shows how unanticipated movements in money, the current account, and relative price levels will cause first a jump in the exchange rate, and then a movement along a "saddle path" to the new long run equilibrium. Here the role of "news" in moving the exchange rate is clear. The model is used to analyze the options available to the central bank that wants to reduce the jump in the exchange rate following a real or monetary disturbance. The distinction is made between monetary policy and sterilized intervention, and a regime in which the domestic interest rate is used as the policy variable is also studied. Systems of vector autoregressions (VARs) for each of four countries--the U.S., the U.K., Germany, and Japan--are estimated, and the correlations among their residuals are studied. These represent the "innovations," or "news" in the time series. A clear pattern emerges in these correlations, in which policy in the U.S. and to a lesser extent Japan, drives exchange rates, and policy in Germany and the U.K. reacts. It appears that U.S. monetary policy is essentially determined by domestic considerations, with the exchange rate moving as a consequence. In Japan, interest rates are varied in response to movement in the current-account and relative price levels, and the effects on the exchange rate are partially neutralized by sterilized intervention. Germany and the U.K. react to movements in their exchange rates by moving interest rates, and sterilized intervention.

William H. Branson

411 Woodrow Wilson School

Princeton University

Princeton, NJ 08544

(609) 452-4828 


\section{Introduction and Sumary}

During the 1970 s an extensive theoretical literature has developed analyzing warket determination of freely floating exchange rates. At the same time, there has been extensive and continuous intervention in the market by central banks. Exchange rates have not been floating freely; they have been managed, or manipulated, by central banks. However, most of the description of exchange rate policy, as actually practiced has been inforwal, or "Iiterary," not integrated with the formal theoretical literarure. Recent examples are the surveys in Branson (1980) and Mussa (1981).

Rather than Ieproduce Mussa's excellent review, in this paper I integrate exchange-rate policy into a model of exchange-rate behevior, and examine the data econometrically, to infer hypotheses about policy behovior in the 1970s. I focus on four major currencies, the U.S. dollar, the Deutschemark, Sterling, and the Japanese yen, and analyze movements in their effective (weighted) exchange rates as calculated by the IMF for their relative cost and price data.

In section II a model of market determination of a floating exchangerate is laid out. It is a rational-expectations version of the model in Branson (1977), and it draws on the model of Kouri-(1978). The model shows how unanticipated movements in money, the current account, and relative price levels will cause first a jump in the exchange rate, and then a movement along a "saddle path" to the new long run equilibrium. Here the role of "news" in moving the exchange rate, as recently emphasized by 
Dormbusch (1980) and Frenkel (1981) Is clear. The model emphasizes imperfect substitutability between domestic and foreign bonds, in order to prepare for the analysis of intervention policy in section III.

Exchange-rate policy is introduced in section III. We analyze the options available to the central bank that wants to reduce the jump in the exchange rate following a real or monetary disturbance--"news" about the current account, relative prices, or money. This ts the policy characterized as "leaning against the wind" in Branson (1976). The distinction is made between monetary policy and sterilized intervention. We also study a regime in which the domestic interest rate is used as the policy variable.

In sections IV and $V$ we turn to the data. These are described systematically in section IV, where we investigate the time-series properties of the exchange rate, money, realtive prices, and the current account, the short-terw interest rate, and reserves for each of the four countries. It is difficult to sumarize these data, but the time-series behavior of exchange rates, money, relative prices, and current-account balances are roughly consistent with the model of section II.

In section $\nabla$ we estimate systems of vector autoregressions (VARs) for each of the countries, and study the correlations among their residuals. These represent the "innovations," or "news" in the time series. A clear pattern emerges in these correlations, in which policy in the U.S. and to a lesser extent Japan, drives exchange rates, and policy in Germany and the J.K. reacts. It appears that U.S. monetary policy is essentially determined by domestic considerations, with the exchange rate moving as a consequence. In Japan, interest rates are varied in response to movement in the 
current-account and Ielative price levels, and the effects on the exchange rate are partially neutralized by sterlized intervention. Germany and the U.R. react to movements in their exchange rates by moving interest rates, and sterlized intervention. 
II. An Asset-Market Model with Rational Expectations

II.A. Introduction

The purpose of this section is to lay out a simple asset-market model of exchange-rate determination within which, in the next section, monetary policy reaction to movements in the exchange rate can be analyzed. The literature of the 1970 s has 1dentified three principal macroeconomic variables that influence movements in exchange rates. These are money supplies, relative price levels, and current-account balances. Here I develop a representative model that explicitly includes all three elements. The model is an extension of the asset-market model sketched in Branson (1975), and developed in full in Branson (1977). It is a close relative of Kouri (1978). In the early versions of this model the focus was on the roles of relative prices and asset markets, and static expectations were assumed. Here the model is extended to study the effects of underlying "real" disturbances influencing the current account and to include explictily policy intervention in a rational expectations framework.

\section{B. Asset-market speciflcation.}

To make the analysis manageable, let us consider one country in a many-country world. We can aggregate the assets avallable in this country into a domestic money stock $M$, which is a noneaming asset, holdings of domestically-issued assets $B$, which are denominated in home currency, and net holdings of forelgn-1ssued assets $F$, which are dominated in foreign exchange. $B^{P}$ (for bonds) is government debt held by the private sector, 
and $B^{C}$ is government debt held by the central bank. Total government dejt $B=B^{P}+B^{C} \cdot F^{P}$ (for foreign assets) is the net claims on foreigners held by the domestic private sector and $R$ is central bank foreign reserves. Total national net claims on foreigners $F=F^{P}+R$. The money stock $M$ is equal to $R+B^{C}$, with a $100 \%$ reserve system. I assume the initial exchange rate is indexed to unity, and that the central bank does not permit capital gains or losses on $R$ to influence $M$. Similarly, interest income on the central bank's holding of $R$ is assumed to be turned over to the Treasury so that it does not affect $M$. The current account in the balance of payments gives the rate of accumulation of $F$ over time. The rate of accumulation of $B$ is the government deficit. $M$ is controlled by central bank purchases (or sales) of $B$ or $F$ Irom (or to) the domestic private sector.

The rate of return on $F$ is given by $\bar{I}$, fixed in the world capital market, plus the expected rate of increase in the exchange rate, ê. The rate of return on $B$ is the domestic interest rate $I$, to be determined in domestic financial markets. Total private-sector wealth, at any point in time, is given by $W=M+B^{P}+e F^{P}$, so here the exchange rate $e$, in home currency per unit of foreign exchange (e.8. $\$ 0.50$ per DM), translates the forelgo-exchange value of $F$ into home currency.

The total supplies of $B$ and $F$ to the national economy are given at each point in time. Each can be accumlated onis over time through foreign or domestic investment. ${ }^{2}$ Given the existing stocks of $B$ and $F$ at ang 
point in time, the central bank can twike discrete changes in $M$ by swapping either $B$ or $F$ with the domestic private sector; these are open-market operations in govermment debt or forelgn assets.

The demand for each asset by the private sector depends on wealth, $W=M+B^{P}+e F^{P}$, and both rates of return, $I$ and $\bar{I}+\hat{e}$. As wealth rises, demands for all three assets increase. The demands for $B$ and $F$ depend positively on their own rates of return and negatively on those of the other assets. The demand for money depends negatively on both I and $\bar{I}+\hat{e} ;$ as either rises, asset-holders attempt to shift from money into the asset whose return has gone up.

These asset-market equilibrium conditions are sumarized in equations (1) $-(6)$.

(1) $\quad M \equiv R+B^{C}=\cdot m(I, \bar{I}+\hat{E}) \cdot W$.

(2) $B^{P}=b(I, \bar{I}+\hat{E}) \cdot W$.

(3) $\quad e \bar{F}^{P}=E(I, \bar{I}+\hat{E}) \cdot W$.

(4) $W=M+B^{P}+e F^{P}$.

(5) $B^{C}+B^{P}=\bar{B}$.

(6) $\quad F^{P}+R=F$.

Equation (4) is the balance sheet constraint, which insures that $m+b+f=1$. The three demand functions give the destred distribution of the domestic wealth portfolio $w$ into the three assets. Specifying the asset demand functions as homogeneous in wealth eliminates the prive level from the esset-market equilibriw conditions. Given the balance sheet 
constraint (4), and gross substitutability of the three assets, we have the constraints on partial derivatives of the distribution functions:

$$
m_{I}+f_{I}=b_{I}<0: \quad m_{I}+b_{\bar{I}}=f_{\bar{I}}<0 .
$$

here a subscript denotes a partial derivative. The three market equilibrium conditions (1)-(3) contain two inopendent equations given the balance sheet constraint (4). In equation (5) the bar over B indicates that the total supply of government debt is fixed.

II.C. Asset accumulation and the current account.

Equations (1)-(6) provide the specification of asset warkets in the model. The other main building block of the model is the current-account equation. The balance-of-payments accounts provide the identity

$$
\dot{F} \equiv \dot{F}+\dot{R} \equiv X+\bar{I}\left(F^{P}+R\right) \equiv X+\bar{I} F .
$$

where $X$ is net exports of goods and non-capital services in terms of foreign exchange. Net exports depend on the real exchange rate e/p, private sector wealth W, (given by equation (4) above), and an exogenous shift factor 3 winich represents real events such as changes in tastes in technology, oil discoveries, etc., which increase net exports for given values of $e / p$ and $w$. Thus we can write

$$
X=X(e / P, W, z) ; X_{e}>0, X_{W}<0 ; X_{z}>0
$$

The sign of $X_{e}$ assumes the Marshall-Lemer condition holds; $X_{h}$ reflects wealth effects on import demand.

Substitution of the function for net exports into the balance-ofpayments identity gives us the equation for accumulation of national net 
foreign assets:

(7) $\dot{F}=X(e / P, W, z)+\bar{r} F$.

It is important to note that open-market swaps between the central bank and the domestic private sector have no direct effect on $W$ or $F$ in (7). And the effect of accurulation of national net foreign assets through a current-account surplus $(\dot{F}>0)$ on $W$ and $F$ is the same regardless of the distribution of $\dot{F}$ between $\dot{F}^{P}$ and $\dot{R}$. Since an increase in $R$, ceteris paribus, increases the money stock, which is part of $W$, any increase in $F$ will raise $w$ by $d F$ independently of the split between $\dot{F}$ and $\dot{R}$. Thus the central bank's intervention policy will have no effect on how a currentaccount balance moves $F$ and $W$ in ( 7 ).

The effect of an increase in $F$ on $\dot{F}$ in (7) is unclear.

$$
\frac{\partial \dot{F}}{\partial \bar{F}}=x_{k}+\bar{r}
$$

with $X_{W}<0$ and $\bar{I}>0$. Below we will conveniently assume that $\partial \dot{F} / \hat{a} \bar{F}=0$; it will quickly become apparent why this is convenient. In Branson (1981), the case where $\partial \dot{F} / \partial F<0$ is analyzed.

Equations (1)-(7) plus the assumption of rational expectations (or, more precisely, perfect foresight in this non-stochastic model) give us a complete dymamic model in $\dot{F}$ and $\hat{e}$. Price dynamics are suppressed, but we will discuss below exogenous price movements as delayed response to monetary shocks.

\section{II.D. Solution of the model.}

Solution of the model proceeds as follows. First, the rational expectations assumption is that $\varepsilon$ is the rate of change of $e$. Then two equations 
of (1)-(3), with wealth substituted from (4) can be used to solve for I and $\hat{e}$ as functions of $M, W, e F^{P}$. The ê and $\dot{F}$ equations then are two dynamic equations in $e$ and $F$ that $c a n$ be solved for the movement in these two variables.

Divide equations ( 1 ) and (3) by $W$ and differentiate totally, holding $\bar{I}$ constant:

$$
\begin{aligned}
& d\left(\frac{M}{W}\right)=m_{I} d I+m_{\hat{e}} d \hat{e} ; \\
& d\left(\frac{e^{-P}}{W}\right)=F_{I} d r+E_{\hat{e}} d \hat{e} .
\end{aligned}
$$

These can be solved in matrix form as:

$$
\left(\begin{array}{l}
d I \\
d \hat{e}
\end{array}\right)=\frac{1}{\left(\pi_{I} f_{\hat{e}}-f_{I} \mathbb{E}_{\hat{e}}\right)}\left[\begin{array}{cc}
f_{\hat{e}} & -m_{\hat{e}} \\
-f_{I} & m_{I}
\end{array}\right]\left(\begin{array}{c}
d\left(\frac{d F^{P}}{W}\right) \\
d\left(\frac{M}{\hat{W}}\right)
\end{array}\right) \text {. }
$$

The solution for dê is then

$$
d \hat{e}=\frac{1}{m_{I} \hat{e}_{\hat{e}}-f_{I} \Phi_{\hat{e}}}\left[-f_{I} d\left(\frac{M}{W}\right)+m_{I} d\left(\frac{e F^{P}}{W}\right)\right]
$$

The coefficients of $\mathrm{eF} / \mathrm{W}$ and $M / W$ are the partial derivatives of the $e$ adjustment function,

$$
\hat{\mathrm{e}}=\phi\left(\frac{\mathrm{e}^{\mathrm{P}}}{\mathrm{W}}, \frac{\mathrm{M}}{\mathrm{W}}\right) ; \phi_{1}>0 ; \phi_{2}<0
$$

This is the dyamic equation to be solved along with (7) for $\dot{F}$ to obtain equilibrium $\mathrm{e}$ and $\mathrm{F}^{\mathrm{P}}$.

In the $e, F^{P}$ space of Figure 1 , the $\hat{e}=0$ locus is a rectangular hyperbola. This can be seen by observing that in $\phi$, eF $F^{p}$ enter multiplicatively (in $W$ as well as the numerator $e F^{P}$ ), so changes in $e$ and $F^{P}$ that 


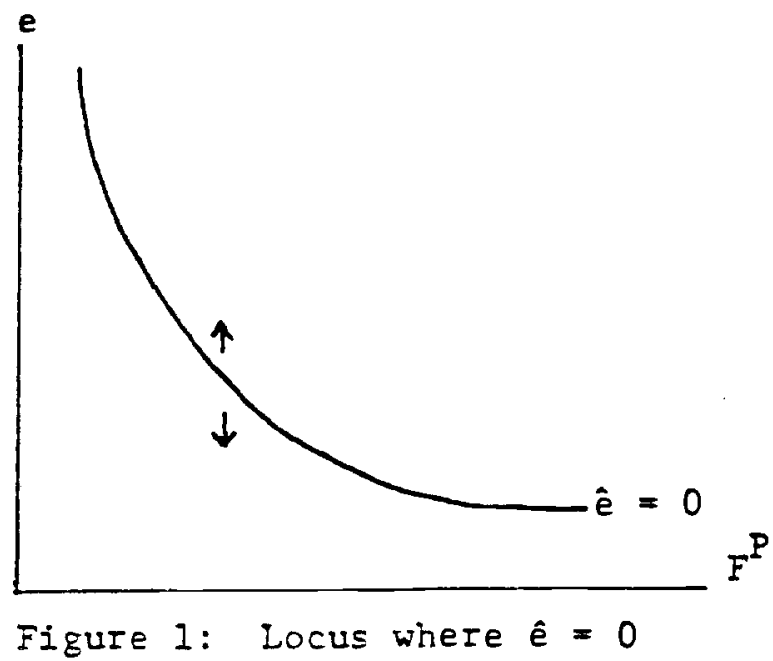

$9 a$.

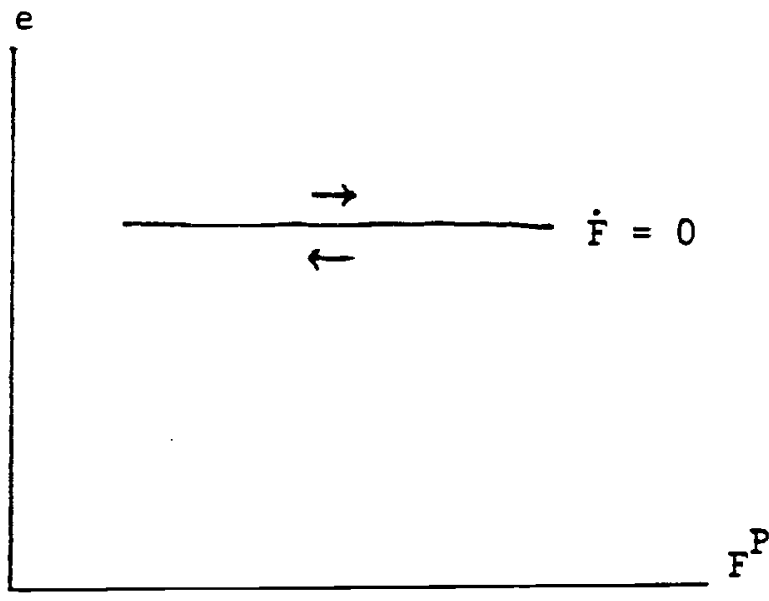

Figure 2: Locus where $\dot{F}=0$

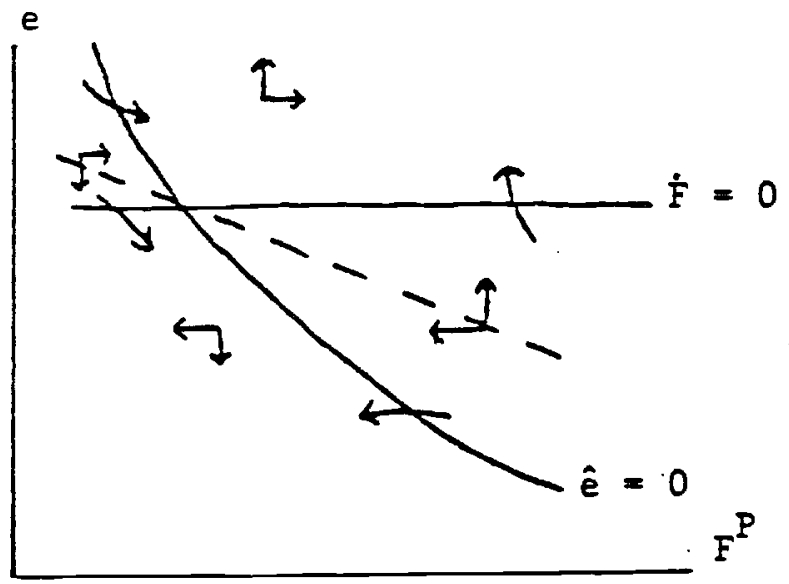

Figure 3: Equilibrium path for $e, F^{P}$ 
hold the product er $\vec{f}^{p}$ constant ill hold ê constant. Comingations of e and $F^{P}$ off the locus move $e$ away from it, as the arrows show. For example, since $\phi_{I}>0$ an increase in $e$ or $F^{P}$ from a point on the locus makes $\hat{e}>0$.

An inczease in $M / W$, holcing $e F^{P} / W$ constant, would shift the $\varepsilon=0$ locus in Figure 1 up. This would be the result of an expansicnary openmarket operation in the government debt market with $d B^{C}=d M>0$, and no change in $R$ or $F^{P}$. An Increase in $\mathrm{eF}^{\mathrm{P}} / \mathrm{W}$, holding $\mathrm{M} / \mathrm{W}$ constant, will shizt $\hat{e}=0$ down; this could result from an open-market swap between $F$ and B. An expansionary open-market operation in the foreign asset market, with the central bank altering reserves by exchanging $M$ for $F$ with the private sector, would shift $\hat{e}=0$ up both by increasing $M / W$ and reducing $e F^{P} / W$. This will provide the difference between intervention in the bond or foreign-asset rarkets in the model.

For given values of $z$ and $P$ in the $\dot{F}$ equation (7), the $\dot{\vec{F}}=0$ locus in $e, F^{P}$ space is a horizontal line at the $e$ value where $X=-\bar{r} F$. This is show in Figure 2. If e is above this value, the current-account is in surplus and $\dot{F}>0$. In section III we will introduce a "leaning against the wind" exchange-rate policy in which the authorities atcempt to reduce tine extent of jumps in the exchange rate, but sot to geverse them. Thus we rule out here the possibility that the monetary authorisy "overIntervenes," and assume that the sign of $\dot{F}^{p}$ is the same as the sign of $\dot{F}$; this is the same as assuring $|\dot{R}|<|\dot{F}|$. This essentialig assmes that the authorities permit the market to guide the system towards its long-Iun equilibrium, but perhaps slow the movement. The assmption gives the arrows showing movement in Figure 2 ; above $\dot{F}=0, \dot{F}^{p}>0$, below it is negative. 
An increase in $z$ in (7) will shift the $\dot{F}=0$ locus down. Given the assumption that $x_{w}+\bar{r}=0$, the extent of the sifit is simply given by the effect of a change in $e$ on $X:$

$$
\left.\frac{d e}{d z}\right|_{\dot{F}}=0=-\frac{1}{x_{e}} \text {. }
$$

If $z$ rises, increasing $X$ and giving a current account surplus, e wust fall (currency appreciate) enough to restore the original value of $X$. An increase in $P$ will shift $\dot{F}=0$ up, with

$$
\left.\frac{d e}{d p}\right|_{\dot{E}}=0=1 \text {. }
$$

Equilibrium of the system is shown in Figure 3 . There is one saddlepath into the equilibrium shown by the dashed line. For a given value of $F^{P}$, it is assumed that following a disturbance, the market will pick the value for $e$ that puts the system on the saddlepath toward equilibrium. The system would have quite different properties unọer a policy regime of "over-intervention" that reversed the pattern of movement in the horizontal difection.

\section{II.E. Reaction to Exogenous Shocks.}

\section{II.E.I Monetary disturbance.}

Consider an (unanticipated) expansionary open-market operation in government debt. This initialig leaves $W$ and $F^{P}$ unchanged. There are two extreme assumptions on price adjustment to consider: no change in $P$, or $\mathrm{dP} / \mathrm{P}=\mathrm{dM} / \mathrm{M}$ imediately.

With no change in $P$ as $M$ increases, the $\dot{F}=0$ locus in Figure 4 does not shift, but $\hat{e}=0$ shifts up. With $\mathrm{F}^{\mathrm{P}}$ initially given, the exchange 


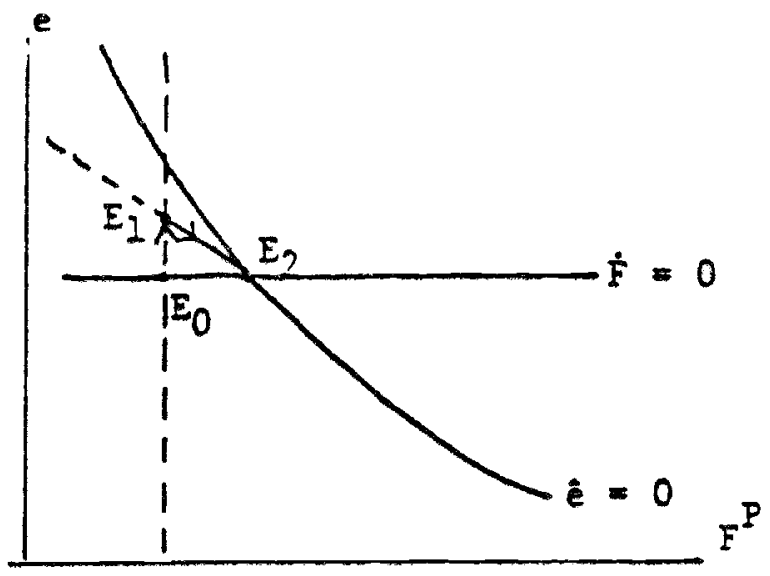

Figure 4: Open-market operation In $B$, no change in $F^{P}$

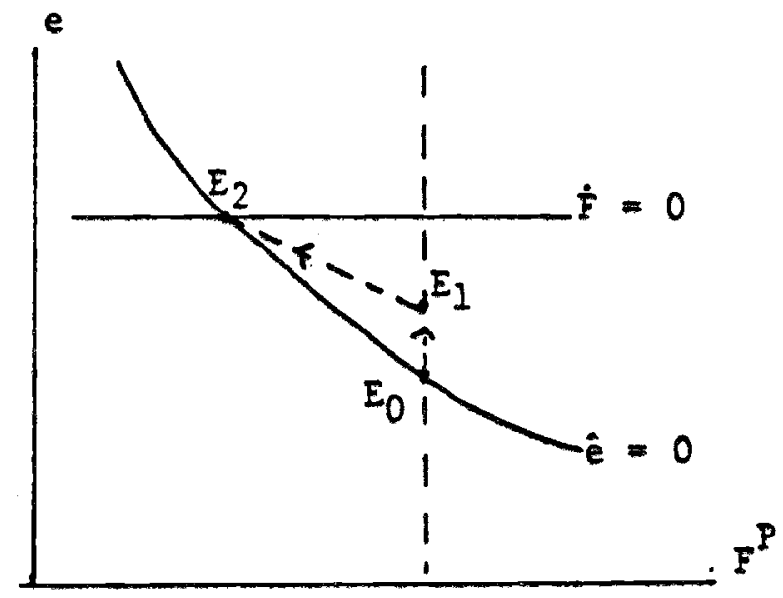

Figure 5: Deterioration in competitiveness

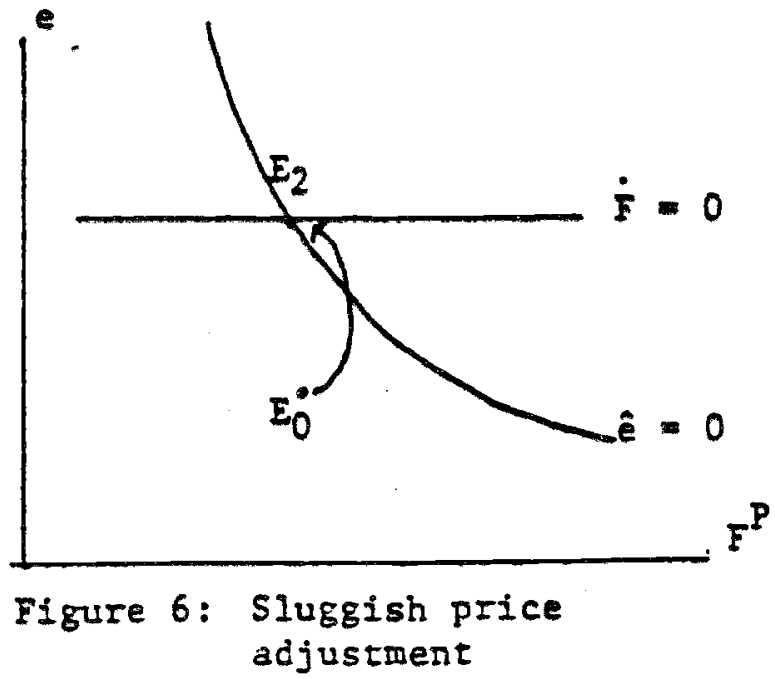


rate jumps (currency depreciates) from initial eculifibrium $E_{0}$ to $E_{1}$ on the new sadilepath. This establishes $\hat{e}<0$ as needed for asset-holders to hold the existing stock of $F^{P}$ given the lower interest rate. The Iise in e/P generates a current-account surplus, and $F^{P}$ rises with e falling toward $E_{2}$. This is an extreme form of "overshooting."

Suppose the domestic price level imediately reacts by rising by the same proportion as the money stock. Then $\dot{F}=0$ also shifts up by that same proportion. The extent of the upward shift in $\hat{e}=0$ depends on initial portfolio distribution and the degree of substitutability among F, $M$, and $B$. One borderline case would be $M=e^{\dot{F}}$ and $m_{I}=f_{I}$. It can be seen in the expression for dê in equation (10) that in this can a propartial increase in $e$ will maintain $\hat{e}=0$. To the extent that $M>\mathrm{eF}^{\mathrm{P}}$ or $\left|f_{I}\right|>\left|m_{I}\right|$, the $\hat{e}=0$ curve would shift up more than $\dot{F}=0$, requiring "overshooting" and $\hat{e}<0, \dot{F} P>0$ moving to equilibrium. The reverse initial conditions would yield "undershooting" with $\varepsilon>0, \dot{F}^{P}<0$ in the movement to equilibrium.

\section{II.E.2. Real disturbance.}

The effect of an unanticipated fall in $z$ (or an increase in P) is shown in Figure 5. The decrease in competitiveness shifts $\dot{F}=0$ up from its initial intersection with $\varepsilon=0$ at $E_{0}$. The exchange Iate jumps (currency depreciates) from $E_{0}$ to $E_{1}$, and then gradually rises to $E_{2}$ as $F^{P}$. falls. The depreciation of the currency restores current-account balance $(\dot{F}=0)$. The model "undershoots" in response to real disturbances. 
II.E.3. SIuggish price adjustment.

A limiting case of sluggish price adjustment could be modelled as a combination of Figures 4 and 5. Expansionary monetary policy would begin this process illustrated in Figure 4. The delayed price response would then resemble Figure 5. To the extent that the price response is logged and unanticipated, the $e, F^{P}$ point would follow a path illustrated in Figure 6. Quicker price response or anticipation would straighten the path to $E_{2}$, which may be to the right or left of $E_{0}$ depending on initial portfolio distribution and substitutability.

II.F. Conclusions and empirical implications.

It is convenient to sumarize here the basic conclusions from the analysis so far.

1. Unanticipated changes in money, the price level, or underlying real conditions should cause a jump in the exchange rate toward the new rational-expectations saddle path.

2. Thus we should expect to see correlation between unanticipated movements in $e$ and $M, X$, and $P$ in the data. Some initial evidence was presented to Branson (1981); more is presented below.

3. Movement of the exchange rate following a real disturbance is likely to be monotonic, while monetary disturbances are likely to produce "overshooting." Iagged price adjustment makes "multiple overshooting" possible. This can be seen in a combination of Figures 4 and 6 . 
II.G. Interest-rate control as an alternative to monev-supply control.

In interpreting the empirical results on exchange-rate policy in section $V$ below, it will be convenlent to have a version of the model in which the monetary authorlty manipulates its holdings of government debt in order to hit an interest-rate target, and uses the interest rate as the instrument of monetary policy. Rere we take $I$ as exogenous, fixed by policy, and permit $B^{P} / W$ and $M / W$ to vary as necessary to hold $I$ at its target value.

To solve the model under a regime of interest-rate control, we make $I$ exogenous and $M / W$ endogenous in equations ( 8 ) above, and then solve for dê and $d(M / W)$. This yields an ê equation in the form

$$
\hat{e}=\psi\left(\frac{e^{\mathrm{P}}}{W}, I\right), \psi_{1}>0 ; \psi_{2}>0 \text {. }
$$

The interest rate simply replaces $M / W$ here.

The $\hat{e}=0$ locus is still a rectangular hyperbola in $\mathrm{e}, \mathrm{F}^{\mathrm{P}}$ space. A reduction in $I$, implying an increase in $M / W$ and decrease in $B^{P} / W$, shifts the $\hat{e}=0$ locus up. Thus Figure 4 provides a qualitative description of the effect of a reduction of the interest-rate target in a regime of monetary control. The effects of movement in the interest rate on the path of the exchange rate are clearly the same as the effects of the corresponding change in $M / W$ in the model with monetary control. 


\section{III. "Learing Against the Wind" as Exchange Rate Policy}

III.A. Introduction.

There is already ample evidence that monetary authorities have generally tried to slow the movement of exchange rates. This type of intervention has long been characteristic of U.S. domestic monetary policy; in Branson (1976) I labelled this "leaning against the wind" as exchange rate policy. Artus (1976) and Branson, Balttunen and Masson (BiM) (1977) presented evidence that German monetary policy responded to movements in the exchange rate in this fasion. BHM (1977) estimated a reaction function of the form $\Delta M=a \Delta e+\ldots$, with $\alpha<0$ for Germany. As the exchange rate rose (DM depreciated), the money supply was reduced (relative to its trend). Amano (1979) describes Japanese monetary policy as attempting to stabilize the exchange rate similarly. O.K. exchange rate policy was ciscussed briefly in OECD (1977), where a regression of the form $\Delta r_{\text {m }}=B \Delta e+\ldots$, with $r_{\text {m }}$ the minimum lending rate (MLR) and $B>0$ is reported. This suggests that when sterling depreciated (e Iose), the MLR was increased as a policy reaction. More recently, Mussa (1981) has presented a thorough review of exchange-rate intervention which is consistent with a "leaning-against-the-wind" model.

The purpose of this section of the paper is to characterize policy intervention in terms of the model of section II, to prepare for interpretation of the empirical results in section $V$ below. The objective is not to evaluate policy; it is to describe it. The main difference from the previous models is the description of intervention es instantaneous and discrete changes in asset stocks via open-market operations to reduce the size of discontinuous jumps in exchange rates. This type of policy behavior is discernable in the "innovation" correlations in section $V$ below. 
We will begin with the description of monetary policy reaction to real disturbances via open-market operations in government debt or foreign assets. Then we study sterilized intervention in the foreign asset market.

III.B. Monetary Dolicy.

Consider a real disturbance to the current account that shifts $\dot{F}=0$ up, (rise in e) to restore equilibriur. This is illustrated in Figure 7, where in the absence of policy intervention, the exchange rate would jump from the initial equilibrium $E_{0}$ to $E_{1}$ and then depreciate further to $E_{2}$. If the central bank tightened money by selling bonds to the public, holding $F^{P}$ initially constant, the $\hat{e}=0$ curve in Figure 7 would shift down as shown by the dashed $\hat{e}=0$. This would shift the saddle path down to the path running to $E_{2}^{\prime}$, and reduce the exchange-rate jump to $E_{1}^{\prime}$. Thus instantaneous intervention would reduce the initial jump in $e$. This would be an unexpected change in $M$, since the originating shift in $z$ and $X$ was unexpected. So this type of intervention could reduce the variability of e over time.

If the open-market operation were done in the foreign asset market, a smaller quantitative intervention would give the same shift in $\varepsilon=0$ and in the sadale path in Figure 7 , because $\mathrm{eF}^{\mathrm{P}} / \mathrm{W}$ in equation ( 8 ) would rise. In addition, since $F^{P}$ would rise, the initial jump would be to a point on the new saddle path below $E_{1}^{\prime}$. Thus intervention on the foreignesset market would, in a sense, be more efficient than open-market operations in the bond market. This is essentially the same result that is obtained by Branson (1977) and Kenen (1982) under static expectations. 


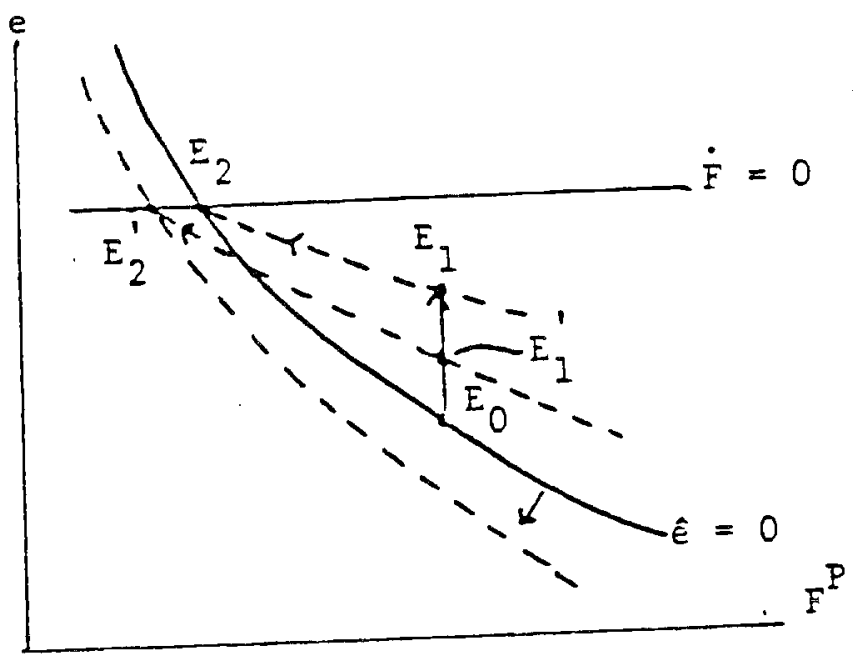

Eigure 7: Monetary policy reaction 
In a model with interest-rate control, the same result as the bondmarket open-market operation of Figure 7 could be obtained by an appropriate increase in the interest rate target. The necessary increase in $I$ could be reduced by performing the open-market operation in the foreign esset raIket.

III.C. Sterilized Intervention.

There is by now ample evidence that central banks intervene in the foreign exchange markets but attempt to prevent the intervention from changing the path of $M$. The literature was cited in Whitman (1975); more recent results are discussed in Obstfeld (1980) (1982). In terms of the model of section III, this is an open-market exchange of foreign assets for bonds by the central bank, with $\Delta B^{P}=-e \Delta F^{P}$ initially. The result is again a downward shift in $\hat{e}=0$, as in Figure 7 , plus an outward shift in $F^{P}$. Thus the jump in the exchange rate is to a point below $E_{I}^{\prime}$, since $F^{P}$ increases. This presents the possibility for intervention that does not move the path of the money supply.

\section{III.D. Monetary disturbances.}

Shifts in asset demand functions on the foreign interest rate would shift the $\hat{e}=0$ locus, and the exchange rate would follow a path such as that of Figure 4, at least 1nitially. Either monetary or sterilized intervention could reduce the extent of the shift in $E=0$, reducing the jump in e. The central bank would vary the supplies of the three assets to meet, at least partially, shifts in their demands by the public. Again, this is a straight-forward extension of "leaning-against-the-wind" policy reaction from the domestic to the international markets. 
III.E. Empitical implications.

The principal empirical implication of the present model of policy intervention is that we should observe the intervention in the correlation of unexpected movements or "innovations" in exchange rates with innovations in money and/or reserves. Monetary intervention would give a negative correlation between exchange-rate and money innovations. Intervention with interest-rate control would give a positive correlation between exchange-rate and interest-rate innovations. If the wonetary intervention is done in the foreign-asset market, a positive correlation between exchange-rate innovations and reserves would result. Sterilized intervention would give the reserve-exchange rate correlation without a moneyexchange rate correlation. Thus we can study the correlation watrix of innovations in section $V$ below to infer hypotheses about policy behavior. 
IV. The Data

IV.A. Introduction.

The asset-market model of section II implies that unanticipated exogenous movements in the money stock, the current-account balance, and relative price levels will cause unanticlpated jump in the exchange rate.

The intervention model of section III implies that unanticipated jumps in exchange rates can cause unanticipated changes in the money stock, reserves, or interest rates. Thus innovations in money or interest rates may have a positive or negative correlation with innovations in exchange rates. If the correlation is negative, the inferred hypothesis would be that the underlying model is a monetary reaction function. A negative correlation between reserve and exchange-rate innovations would indicate exchange-market intervention. In this and the following section of the paper we see that the quarterly data for the U.S., Germany, Japan, and the U.K. can be interpreted in this framework. We are inferring testable hypothesis from the data in this exercise.

In this and the next section, we study relationships of movements in the exchange rate of each country, measured by the effective exchange rate as defined by the IME, with movements in money stocks, current-account balances, relative prices, reserves, and interest rates. The purpose 1s to see what polfcy stance is Implied by the data. The data are described in detail in Table 1.

The first step in analyzing the data is to investigate their timeseries properties. This provides a compact description of the "facts," 
and an initial incication of whether the facts are roughly consistent with the theory. The time-series analysis of the data is done in this section. Then in section $V$ we study systems of vector autoregressions, one for each country, to test the relations between unanticipated changes, or "innovations," in the variables.

IV.B. Iime series analysis.

In this section the autoregressive structure of each time series is described by regression equations of the form:

(12) $x_{t}=a_{0}+\sum_{i=1}^{I} a_{i} x_{t-i}+\sum_{j=1}^{3} B_{j} D_{j}+\gamma t+u_{t}$, 
Table 1: VARIABLE DEFINITIONS AND DATA

I. Variable Name

e

$P / \bar{P}$

MI

M3

CAS

IS

$\mathbf{R}$ effective nominal exchange rate, in units of foreign currency per unit of home currency as computed by the IMF. Note that this definition is the inverse of $e$ in sections II and III.

relative wholesale prices (ratio oi home to competitors indices).

nariow money, as defined by the MIF in the Intemational Etnancial Statistics (IFS).

broad money, as defined by the IXF (MI plus quasi-money) is the IFS.

current account balance. short-term interest rate, frow IFS.

Ieserves, fIom IFS. 
II. Counzises

United States

United Kingdom

Federal Republic of Germany

Japan

III. Deta

1. All data are quarterly, from IMF sources (in most cases fzom IFS) and cover 1973:IV to 1980:IV.

2. Exchange Rares: $e$ is the $\log$ of the average effective exchange rate during quartet $t$. The units are foreign currency per unit of domestic currency. The incex is based on a geonetrically weighted average of bilateral rates between the home and 13 other industrial countries. The weights are the same as those used to calculated $P / \bar{P}$. Base: $1975=100$. Source: IMF. Note that these are not the MERM rates published in IFS.

3. Relative Prices: The index is a log of the ratio of home to foreign quarteriy wholesale prices indices. $\bar{P}$ is a composite and uses the same weights as e does (see above). Base $=1975$. Source: IMF. This index is not the same as that published in the IFS. OuI data is based on indices in local (not a comon) currency.

4. Money: This is the $\log$ of the end of the quarter money stock. Source: IFS, line 34 ("money") for Ml, lines 34 and 35 ("money" + "quasi-moner") for $M 3$.

5. Current Account: This is the dollar value of the flow during the quarter (not measured in logs). Source: IFS, Lines: $77 a a$ (Merchandise: Exports, fob); $77 a b$ (Merchandise: Inports, fob); $77 a c$ (Other Goods, Services, and Income: Credits): 77ad (Other Goods, Services, and Income: Deblts); 77 ae (Private Unrequited Iransfers); $77 a g$ (Official Dnrequited Iransfers).

6. Short-term interest rate: Data are taken from IFS as indicated In the Table on "Money Karket and Euro DoIlar Rates." Source: IFS country pages: U.S, and U.K., line 60c; Germany and Japan, line 60b.

7. Reserves: These are the dollar value of reserves measured at end of perlod. Source: IFS line ld.d. These series did not vary significantly from the series adjusted for valuation changes provided by the IMF. 
where $x_{t}$ is the $l 0 g$ of the time series under consideration, $x_{t-i}$ is its value lagged $i$ quarters, $D_{i}$ is a seasonal dumy, and $t$ is time. Equation (12) is a univariate autoregression of the variable $X$ on its own past values, and the estimated values of the $\alpha$ coefficients give the pattern of response of the time series to a disturbance $u_{t}$. The two cases that will prominentiy appear in our data are first-order autoregression, where only $\alpha_{1}$ is significant, and second-order autoregression, where $\alpha_{1}$ and $\alpha_{2}$ are significant. One purpose of the analysis is simply to describe the data; the second is to see if the time-series structure of the exchangerate data is consistent with that of the other data.

For each variable we began with a regression on four lags, seasonal dumies, and a time trend. We then shortened the lags by eliminating insignificant variables at the far end of the lag. The results are shown in Tables 2 through 5, one for each country. Each colum in the tables shows the results of a regression of the indicated variable on lagged values of itself. Coefficients of the time trend and seasonal dumies are not shown. The regressions are performed on quarterly data for the period 1973-IV to 1980-IV. The beginning date was chosen because it was after the major period of disequilibrium adjustment in 1971-73, including a major real devaluation of the U.S. dollar, and the last date was the most recent for which data were available when we began the study in June 1981. The regressions were run using the Jogs of exchange rates, relative prices, and money, and the levels of the currentaccount balance, interest rates, and reserves. The current-account and reserves are both time series that pass through zero in some cases. 
IV.C. Country results.

IV.C.I. United States

The results for the U.S. are instructive, and serve as an illustration of the technique. In the first two colums of Table 2, we show the Iegressions for the log of the U.S. nominal effective exchange rate $e$, weighted by the IMF, In foreign currency per dollar. The first column shows the regression with four lags on the exchange rate; only the lag at $t-1$ is significant with a coefficient of 0.86 . When the lags at $t-2$ through $t-4$ are eliminated, the standard error of the estimated equation falls a bit, and the coefficient of $e_{t-1}$ is 0.78 . Thus the U.S. effective rate, measured as a quarterly average, can be described as a stable firstorder autoregression (ARI). The coefficient of 0.78 in $e_{t-1}$ indicates that a given disturbance $u_{t}$ will eventually disappear from the time series as its effect is given by increasing powers of $.78: e_{t}=.78 u_{t} ; e_{t+1}=$ $.78^{2} u_{t}$, etc.

The third and fourth colums of Table 2 show the results for the log of the U.S. Ielative price index $P / \bar{P}$. This is an index of the U.S. WPI Ielative to a weighted average of the WPI's of thirteen other industrial countries. The variable $P / e^{\bar{P}}$ is the IMF's measure of relative cost, published in the International Financial Statistics. It is the inverse of the "real exchange rate" of section II. 


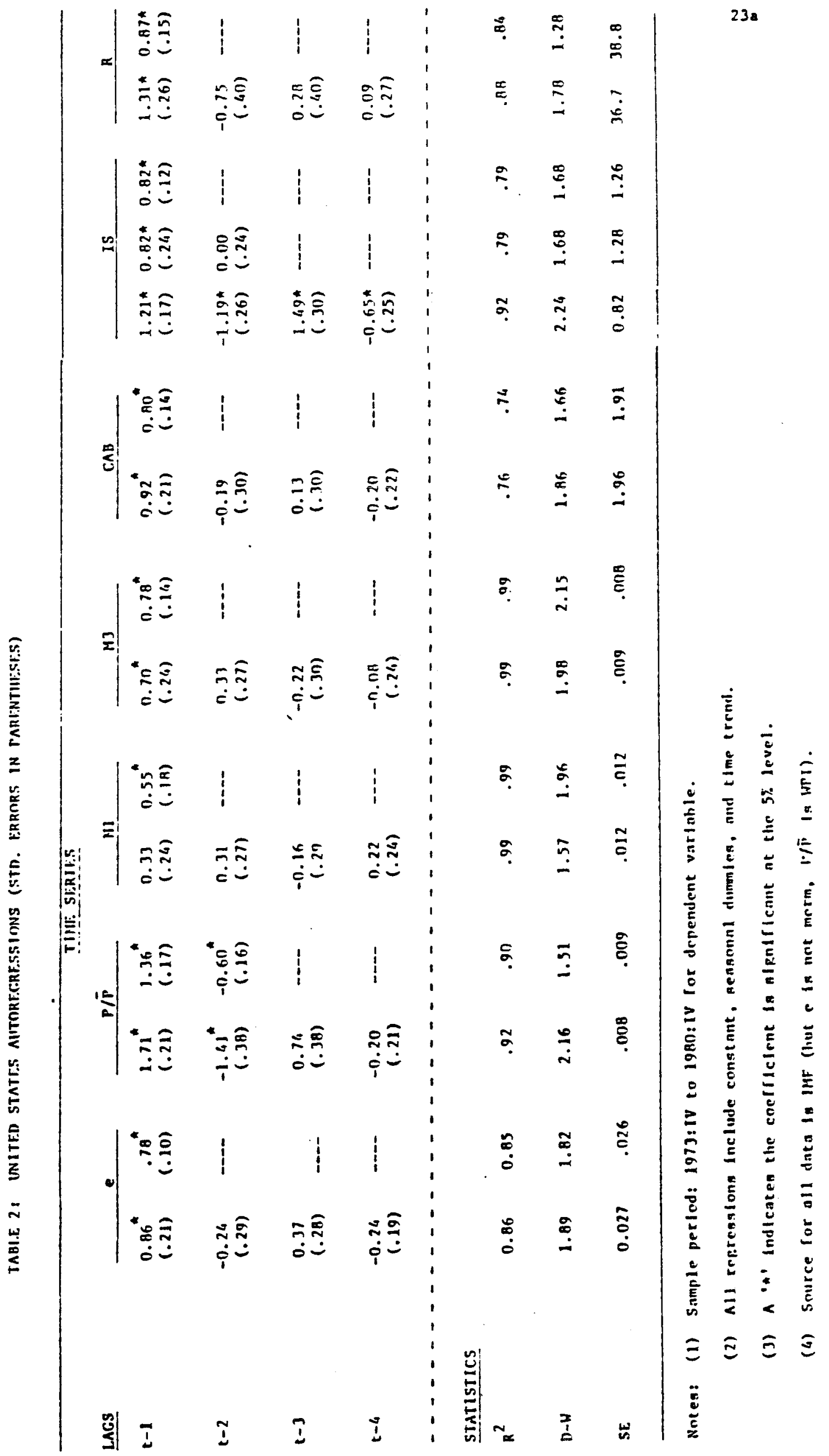


The first regression for $P / \bar{P}$ in Table 2 gives significant coefficients to the lags at $t-1$ and $t-2$. Eldmination of the longer lags results in the second equation, with a standard error only slightly larger than the first. The result for $P / \bar{P}$ is a second-order autoregression (AR2), with a stable cyclical response to a disturbance. ${ }^{3}$

The next two pairs of colums in Table 2 show the univariate autoIegression results for the two U.S. money stocks. In both cases only the lag at t-l is bignificant. Both are stable first-order autocorrelations.

The next two columas in Table 2 show the autoregressions for the current-account balance. These are run on the level of CAB, rather than its log, since the time series passes through zero. The result is similar to that for the money stocks.

The next three colums in Table 2 show the autoregressions for the U.S. short-term interest rate. All four lag coefficients are significant in the first column. In the second regression, with just lags at $t-1$ and $t-2$, the second is completely insignificant. Beyond $t-1$, the important lags are at $t-3$ and $t-4$. The last of the three regressions includes only the lag at $\mathrm{t}-1$; the standard error is clearly higher than in the four-lag regression. Rather than include in the VAR system for the U.S. in section 
$\nabla$ four (or more) lags on the interest rate, which would greatly reduce degrees of freedom, I decided to Include only the $l$ ag at $t-1$. The last two columns of Table 2 show the regressions for U.S. reserves. Only the $12 g$ at $t-1$ is significant, giving a stable first-order autoregression.

In the case of the U.S., then, money stocks, the balance on curIent account, reserves, and the nominal effective exchange rate all follow stable ARI processes. This suggests that the behavior of money stocks, the current-account balance, reserves, and the exchange rate are consistent, at this level, with the theoretical model of section II and III.

The relationships between interest rates and relative prices, and the exchange rate is more complicated. With relative prices following an AR2, there is at best a loose relationship to the exchange rate. This is consistent with the evidence of high variability in PPP in Frenkel (1981). The higher-order process for the interest rate suggests that it is being moved by all the exogenous variables simultaneously, rather than reacting systematically to, or causing directly, the exchange rate.

IV.c.2. West Germany.

Table 3 shows the unfvariate autoregression results for Germany. The format is exactly the same as for the U.S., so the discussion can be brief. - As in the U.S. case, the nominal effective rate, the money stocks, and the balance on current account all follow ARI processes in Germany. All but $M 3$ are stable. German $M 3$ has a lag coefficient of unity, indicatIng that it is a "random walk": the change in $M 3$ is (roughly) white noise. 


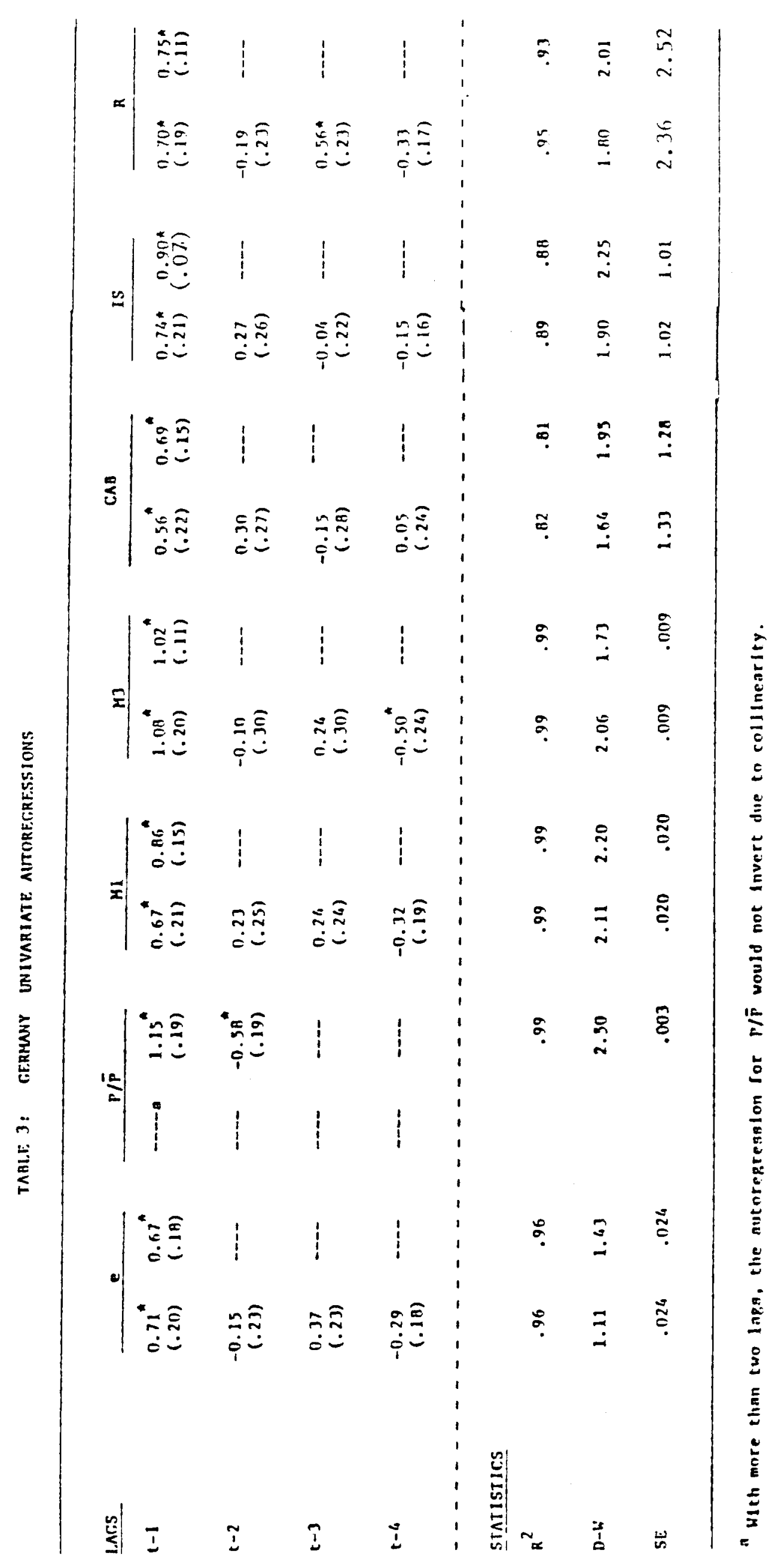


The German relative price series is AR2 w1th a stable cyclical response to disturbances. ${ }^{4}$ The German Interest rate is ARI with a lag coefficient close to unity. Reserves have a barely significant lag at $t-3$, but but can be approximated by a stable ARI. Thus the impression from the German data is similar to the U.S., except for the additional possibility that the interest rate is used as a policy instrument to control movements in the exchange rate.

IV.C.3. Enlted Kingdom

The U.K. results are surized in Table 4. Both the nominal effective rate and the $M I$ money stock in the U.K. have coefficients of unity on the t-l lag, indicating that they follow a random walk. The relative price series is AR.2, as in the U.S. and Germany, but with a stable monotonic adjustment response to disturbances.

In the first regression for the current-account balance, there are no significant lag terms. Thus the U.K. CAB is best described as random around the path described by the trend and seasonal dumy terms. This suggests that the innovations in the CAB in the U.R. should not be interpreted as conveying information about future movements in the exchange rate. 5

Both the interest rate and reserves in the U.K. follow second-order autoregressions, with stable cyclical responses to disturbances. This would be consistent with Interest rate policy being used to control reserves. 


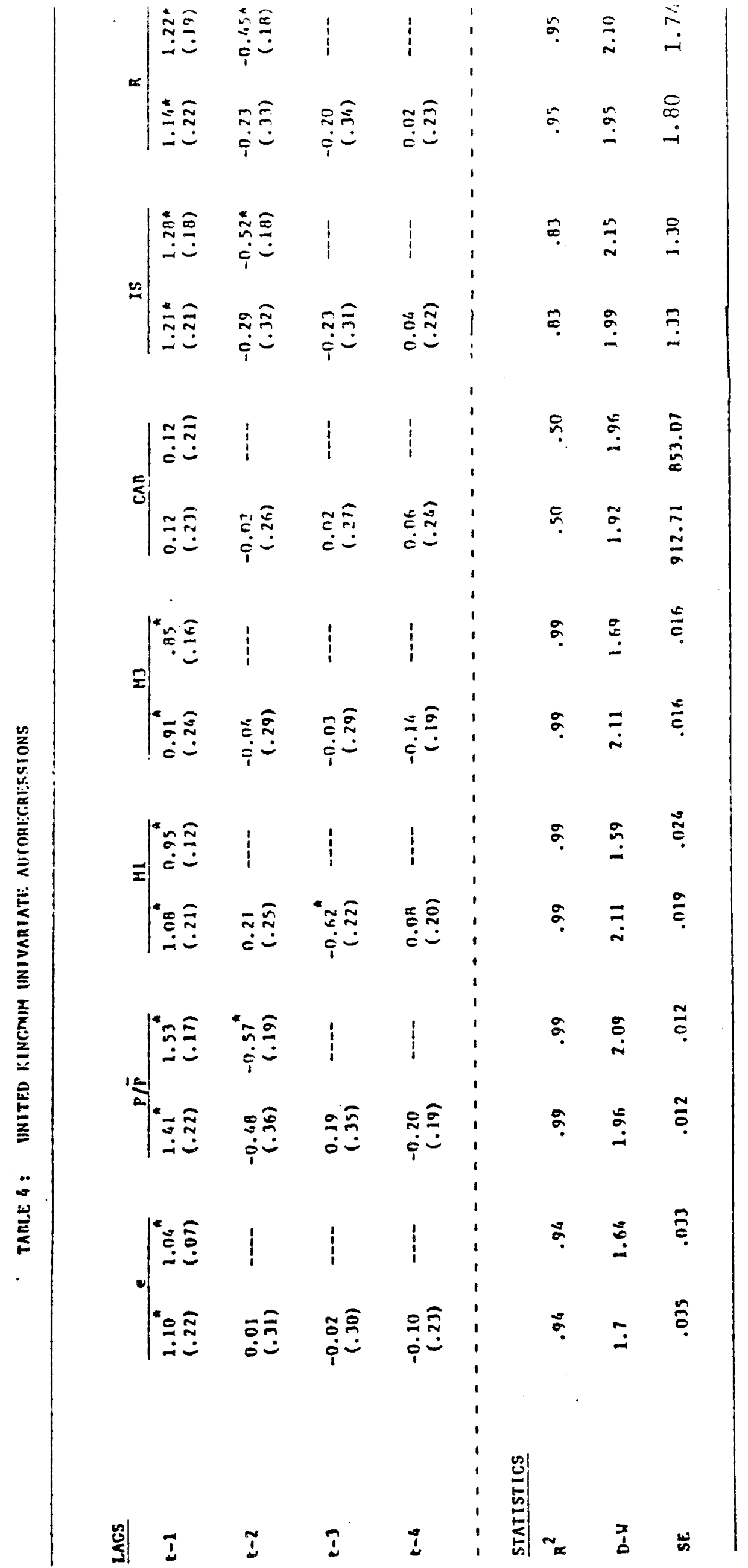


IV.C.4. Japan

The results for Japan are sumarized in Table 5. There we see major differences from the other three countries. The norinal effective exchange rate, the relative price series, the current-account balance, and the interest rate are all AR2 with stable cyclical response patterns. The two money stocks are ARI with unitary lag coefficients. Reserves in Japan follow a complex autoregression of at least the fourth degree. Comparison of the first two reserve regressions in Table 5 shows the importance of the $\mathrm{lag}$ at $t-4$. To conserve degrees of freedom in the Japanese VAP. system reported in section $\nabla$, I used the f1rst-order approxImation. 6 . Thus in the Japanese case the time-series behavior of the exchange rate is consistent with that of relative prices, the current account, and the interest rates, but the exchange rate does not follow the random-walk pattern of money.

\section{IV.D. Sumary on the data.}

The univariate autoregressions of Tables 2 through 5 provide a useful and.compact description of the "ffacts." Comparing the country results, we see several comon points.

1. All weighted relative price series are second-order autoregressions with stable responses to shocks. All but the U.R. serles are cyclical.

2. All the money stocks are first-order autoregressions, many with unitary lag coefficlents. 


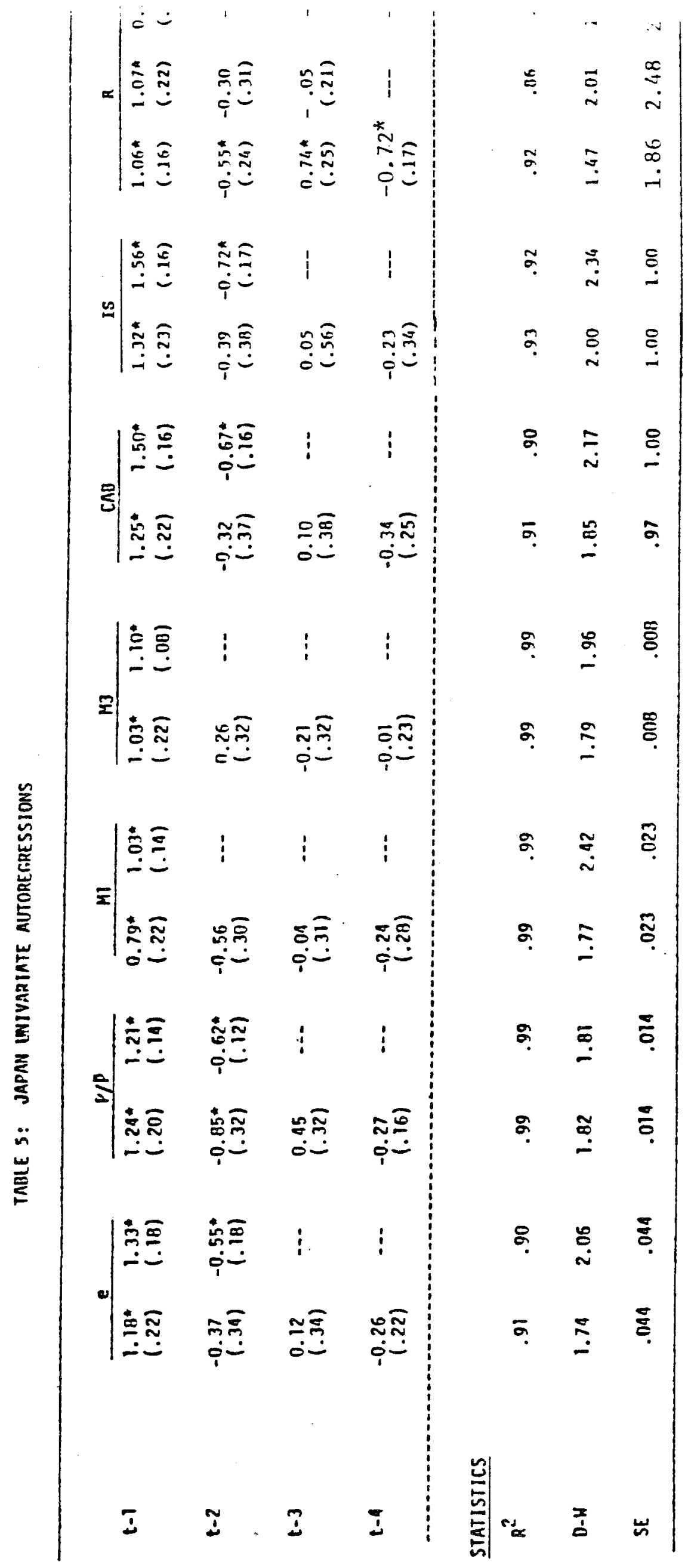


3. The U.S. and German exchange-rate and current-account series are first-order autoregressions, and the Japanese are second-order. Thus these moyements in exchange rate are consistent with movements in the current-account balance, while the U.K. CAB contains no information about its future path.

4. The U.S. and German exchange-rate and reserves follow ARI processes that could reflect intervention. The U.K. and Japanese interest rates and exchange rates follow consistent processes, ARI and AR2 respectively. 


\section{Empirical Results Using Vector Autoregression}

V.A. Introduction.

A useful technique for studying the relationships between the innovations in money, the current account balance, relative price levels, interest rates, reserves, and the exchange rate is vector autoregression (VAR). Here each variable of a system is regressed against the lagged values of all variables (including itself) in the system, to extract any information existing in the movements of these variables. The residuals from these "vector autoregressions" are the innovations - the urantici- . pated movements -- in the variables. We can study the correlations of the resiouals to see if they are consistent with the hypotheses implied by the theory of sections II and III. The vector autoregression technique is introduced and justified by sims (1980). A clear exposition is presented in Sargent (1979). Interesting and instructive applications are discussed in Taylor (1980), Ashenfelter and Card (1981), and Fischer (1981).

Here I estimate systems of VARs for each of the four countries, the U.S., the U.K., Germany, and Japan. Two systems were estimated for each country. Both include the effective exchange rate $e$, the current account balance $C A B$, and the effective relative price $P / \bar{P}$, the interest rate IS, and reserves $R$; the difference between the two is that one includes MI

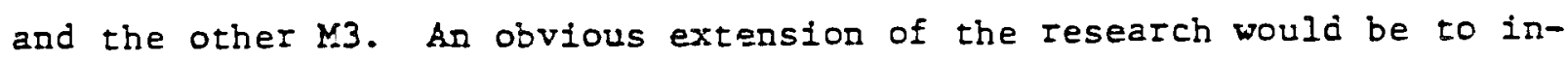
clude cross-country effects, particularly of money stocks, but also the other variables. The difficulty in proceeding in this direction comes from the limited number of quarterly observations: 29 from 1973-IV to 
1980-IV. Each VAR includes lagged values of four variables, a time trend, and three seasonal dumies. In order to expand the analysis, I am presently moving to a monthly data base.

Before estimating the VARs, one must consider the issue of the timing of the data. The effective exchange rate can be computed from public information on a daily basis. In fact, a UK effective rate is published daily in the Financial Times. Our data are averages during the quarter. The effective rate used here is the inverse of e as defined in sections II and III. Money stock data are available on a weekly basis, so they are roughly contemporaneous with the exchange rage data. Our money data are end-of-period. We would expect from section II that the weekly changes In $M$ would generate nearly simultaneous movements in $e$. Thus the innovation of the average e over a quarter would be most closely connected in our data with the innovation of the end-of-quarter money stock, which is the cumulation of the weekly innovations. Reserves are also enc-of-period data, so that intervention to slow an unanticipated jump in e would appear as an innovation in reserves.

The relative price data are quarterly averages of monthly data, which become known soon after the month finishes. Thus in our data set, the innovation in $e_{t}$ wauld be most closely connected to the innovation in $P / \bar{P} t_{t}$ Interest rates are also quarterly averages, so that if the interest rate were used to control the exchange rate we would see a correlation between the Innovations in $e_{t}$ and in IS $_{t}$.

On the other hand, the data on the quarterly balance in current account are not announced until well into the following quarter. Thus to 
the extent that the innovation in CAB signals a change in the equilibrium real exchange rate, it is the innovation in $\mathrm{CAB}_{t-1}$ that moves $e_{t}$.

The VAR residuals to be correlated, then, are those of $e_{t}, M_{t},(P / \bar{P})_{I}$, $C A B_{t-1}$, IS $t$, and $R_{t}$. We will use a $n$ to designate residuals from the vaRs. The variables in each VAR system are listed in Table 6 . The number of lags included in each variable was deterwined by the univariace autoregression of Table 2 through 5. This constraint provides a convenient way to limit the number of regressors and conserve degrees of freedom. A next step in research would be to re-estimate the VAR systems with adiitional lags to see how much information is lost by application of this constraint.

After the VAR systems are estimated, we correlate their residuals to study the relationship among innovations. The correlations are given for the systems with $M I$ and $M 3$ in Tables 7-14 below, two for each country. Each table includes the correlation coefficients among the VAR "innovations" and in parentheses the probability of that correlation occurring under the null hypothesis that the true correlation is zero.

In discussing the cortelations, we will focus on the correlations particularly relevant for analyzing exchange-rate determination and policy. Detailed discussion of all the results would be far too tedious.

\section{V.B. United States}

The correlations of VAR Innovations for the U.S. are shown in Tables 7 and 8 . Remember that here the effective nominal exchange rate is defined in units of forelgn exchange per unit of home currency, the inverse of the theoretical definition of sections II and III. So here an increase In $e$ is an appreciation. 
Table 6: Variables Included in Vector Autoregression Systems

\begin{tabular}{|c|c|c|}
\hline U.S., Germany & U.K. & Japan \\
\hline $\ln e_{t-1}$ & $\ln e_{t-1}$ & In $e_{t-1}$ \\
\hline $\ln M_{t-1}$ & $\ln M_{t-1}$ & $\ln e_{t-2}$ \\
\hline $\ln P / \bar{P}_{t-1}$ & $I_{D} P / \bar{P}_{t-1}$ & $\ln M_{t-1}$ \\
\hline $\ln P / \bar{P}_{t-2}$ & $\ln P / \bar{P}_{t-2}$ & $\ln P / \bar{P}_{t-1}$ \\
\hline$C A B_{t-2}$ & $C A B_{\tau-2}$ & $\ln P / \bar{P}_{t-2}$ \\
\hline IS $_{t-1}$ & IS $_{t-1}$ & $\mathrm{CAB}_{t-2}$ \\
\hline$R_{t-1}$ & IS $_{t-2}$ & $\mathrm{CAB}_{t-3}$ \\
\hline & $R_{t-1}$ & IS $_{t-1}$ \\
\hline ? & $R_{t-2}$ & IS $_{t-2}$ \\
\hline & & $R_{t-1}$ \\
\hline
\end{tabular}

Note: Two VAR systems were estimated for each country, one with Ml, one with M3. The equations are estimated on data 1973 IV-1980 IV (described in Table 1). 
Table 7: Correlations of Innovations From U.S. Vector Autoregression System With $M I$

\begin{tabular}{|c|c|c|c|c|c|c|}
\hline & e & $\dot{M I}$ & $\bar{P} / \bar{P}$ & $\tilde{C A B}$ & Is & $\dot{\mathrm{R}}$ \\
\hline$\tilde{e}$ & 1.00 & $\begin{array}{l}-.30 \\
(.11)\end{array}$ & $\begin{array}{l}-.42 \\
(.03)\end{array}$ & $\begin{array}{l}-.12 \\
(.55)\end{array}$ & $\begin{array}{l}-.09 \\
(.65)\end{array}$ & $\begin{array}{l}.14 \\
(.46)\end{array}$ \\
\hline MI & & 1.00 & $\begin{array}{l}-.35 \\
(.06)\end{array}$ & $\begin{array}{l}-.41 \\
(.03)\end{array}$ & $\begin{array}{l}-.03 \\
(.87)\end{array}$ & $\begin{array}{l}-.56 \\
(.00)^{a}\end{array}$ \\
\hline $\mathrm{P} / \overline{\mathrm{P}}$ & & & 1.00 & $\begin{array}{l}.44 \\
(.02)\end{array}$ & $(.24)$ & $\begin{array}{l}.26 \\
(.17)\end{array}$ \\
\hline$\overline{C A B}$ & & & & 1.00 & $\begin{array}{l}-.11 \\
(.58)\end{array}$ & $\begin{array}{c}.55 \\
(.00)^{a}\end{array}$ \\
\hline Is & & & & & 1.00 & $\begin{array}{l}.35 \\
(.07)\end{array}$ \\
\hline$\dot{R}$ & & & & & & 1.00 \\
\hline
\end{tabular}

a. An entry of .00 indicates the number was less than .005 . 
Table 8: Correlation of Innovations From U.S. Vector Autoregression System With M3

\begin{tabular}{|c|c|c|c|c|c|c|}
\hline & $\bar{e}$ & M3 & $-\bar{P} / \bar{P}$ & $\dot{C A B}$ & IS & $\tilde{R}$ \\
\hline$\tilde{e}$ & 1.00 & $\begin{array}{l}-.48 \\
(.01)\end{array}$ & $\begin{array}{l}-.37 \\
(.05)\end{array}$ & $\begin{array}{l}-.08 \\
(.68)\end{array}$ & $\begin{array}{l}-.02 \\
(.92)\end{array}$ & $\begin{array}{l}.24 \\
(.22)\end{array}$ \\
\hline$\tilde{M} 3$ & & 1.00 & $\begin{array}{l}.23 \\
(.24)\end{array}$ & $\begin{array}{l}.05 \\
(.81)\end{array}$ & $\begin{array}{l}.50 \\
(.01)\end{array}$ & $\begin{array}{l}.07 \\
(.73)\end{array}$ \\
\hline $\bar{P} / \bar{P}$ & & & 1.00 & $\begin{array}{l}.38 \\
(.04)\end{array}$ & $\begin{array}{l}-.03 \\
(.89)\end{array}$ & $\begin{array}{l}.03 \\
(.90)\end{array}$ \\
\hline$\overline{C A B}$ & & & & 1.00 & $\begin{array}{l}-.24 \\
(.21)\end{array}$ & $\begin{array}{l}.47 \\
(.01)\end{array}$ \\
\hline is & & & & & 1.00 & $\begin{array}{l}.30 \\
(.12)\end{array}$ \\
\hline$\tilde{R}$ & & & & & & 1.00 \\
\hline
\end{tabular}


The first rows of Iables 7 and 8 give the corzelations of exchange-rate innovations. The negative signs for relative prices and money are consistent with innovations in those variables driving $e$, as in the model of section II. There is a weak correlation with reserves, consistent with intervention. Innovations in reserves, shown in the last columns of Tables 7 and 8 , are positively correlated with innovations in $C A B$, but not in money. It is useful here to Iecall that the $C A B$ is lagged one period, so that the correlation is between the residual $\tilde{C A B}_{t-1}$ and $\hat{R}_{t}$. Thus the indication in Table 7 and 8 is that intevention comes at the point where the $C A B$ announcement would move the exchange rate, not during the period in which the actual $C A B$ occurs.

The underlying vector autoregression for e (not shown here) also shows a strong Granger-causal role for lagged CAB. Thus the hypothesis I would infer from the U.S. data is as follows. The current account, mosey, and relative prices all move the exchange rate, the latter fwo through market expectations and innovations. Monetary policy is essentialIy oriented toward domestic targets; movement in the exchange rate is a side effect. The U.S. monetary authorities intervene and sterilize, but do not follow a tight rule. This shows up in the strong correlation be$\dot{R}$ and $\overline{C A B}$, and in the correlation between $\bar{R}$ and $\dot{e}$.

\section{D.C. Germañ}

The innovation correlations for Germany are shown in Iables 9 and 10. In the first row of both tables we see a very strong negative correlation berween exchange-rate and Ielative price innovations. This could come from exchange rates causing prices or vice versa, but through innovations and market expectations Iather than a tight PPP relationsip. The correlations of exchange-rate innovations with short-terw interest rates and reserves (in the MI system) must Ieflect leaning-against-the-wind policy both in terms of 
Table 9: Correlation of Innovations From German Vector Autoregression System With MI

\begin{tabular}{|c|c|c|c|c|c|c|}
\hline & $\bar{e}$ & $\dot{M I}$ & $\bar{P} / \bar{P}$ & $\tilde{C A B}$ & is & R \\
\hline$\tilde{e}$ & 1.00 & $\begin{array}{c}.17 \\
.(.37)\end{array}$ & $\begin{array}{l}-.44 \\
(.02)\end{array}$ & $\begin{array}{l}.27 \\
(.15)\end{array}$ & $\begin{array}{l}-.48 \\
(.01)\end{array}$ & $\begin{array}{l}.40 \\
(.03)\end{array}$ \\
\hline$\dot{M I}$ & & 1.00 & $\begin{array}{l}.02 \\
(.94)\end{array}$ & $\begin{array}{l}.25 \\
(.19)\end{array}$ & $\begin{array}{c}-.47 \\
(.01)\end{array}$ & $\begin{array}{l}.28 \\
(.14)\end{array}$ \\
\hline $\bar{P} / \bar{P}$ & & & 1.00 & $\begin{array}{l}.23 \\
(.22)\end{array}$ & $\begin{array}{l}.07 \\
(.73)\end{array}$ & $\begin{array}{l}.28 \\
(.14)\end{array}$ \\
\hline$\tilde{C A B}$ & & & & 1.00 & $\begin{array}{l}-.33 \\
(.08)\end{array}$ & $\begin{array}{l}.43 \\
(.02)\end{array}$ \\
\hline IS & & & & & 1.00 & $\begin{array}{l}-.13 \\
(.49)\end{array}$ \\
\hline$\overline{\mathrm{R}}$ & & & & & & 1.00 \\
\hline
\end{tabular}


Table 10: Correlation of Innovations From Gerwan Vector Autoregression System With M3

\begin{tabular}{|c|c|c|c|c|c|c|}
\hline & $\bar{e}$ & $\overline{\mathrm{M}}$ & $\bar{P} / \bar{P}$ & $\overline{C A B}$ & is & $\mathrm{R}$ \\
\hline $\bar{e}$ & 1.00 & $\begin{array}{l}-.09 \\
(.63)\end{array}$ & $\begin{array}{l}-.59 \\
(.00)\end{array}$ & $\begin{array}{l}.03 \\
(.90)\end{array}$ & $\begin{array}{l}-.52 \\
(.00)\end{array}$ & $\begin{array}{l}-.26 \\
(.17)\end{array}$ \\
\hline M3 & & 1.00 & $\begin{array}{l}.18 \\
(.34)\end{array}$ & $\begin{array}{l}.20 \\
(.30)\end{array}$ & $\begin{array}{l}-.53 \\
(.00)\end{array}$ & $\begin{array}{l}-.04 \\
(.84)\end{array}$ \\
\hline $\bar{P} / \bar{P}$ & & & 1.00 & $\begin{array}{l}.25 \\
(.20)\end{array}$ & $\begin{array}{c}.05 \\
(.79)\end{array}$ & $\begin{array}{l}.45 \\
(.01)\end{array}$ \\
\hline$\overline{C A B}$ & & & & 1.00 & $\begin{array}{l}-.29 \\
(.13)\end{array}$ & $\begin{array}{l}.25 \\
(.19)\end{array}$ \\
\hline IS & & & & & 1.00 & $\begin{array}{l}-.01 \\
(.96)\end{array}$ \\
\hline $\bar{R}$ & & & & & & 1.00 \\
\hline
\end{tabular}


interest rates and intervention. The negative correlation of the interest rate and $C A B$ innovations suggests that interest-rate policy may respond to the state of the $\mathrm{CAB}$ as well as to the exchange rate. The lack of correlation between money and reserves or exchange rates indicates sterilized intervention. The correlation between $\overline{C A}$ and $\vec{R}$ also supports the intervention hypothesis.

Thus the German data suggest fairly strongly a situation in which (a) price and exchange-rate innovations go together, and (b) the authorities react to exchange-rate and current-account movements through changes in interest rates and sterilized intervention. This is consistent with the earlier results of BHM (1977) and of Herring-Marston (1977) for the fixed-rate regime.

\section{V.D. United Kingdom}

The U.K. correlations are shown in Tables 11 and 12 . The exchangerate correlations with interest rates and reserves are a strong indication of leaning-against-the-wind intervention and interest-rate policy. This effects.MI but not $M 3$, as can be seen in the correlations of $\bar{M}$ with $\bar{e}$ and $\vec{R}$. Innovations in the current-account balance have the positive correlation with $e$ that would come from the theory of section II. Perhaps this suggests that while from the undivariate autoregressions of section IV, $C A B$ innovations have no predictive content, the market thinks they do. In both tables there is a strong negative correlation between the $C A B$ innovation and the interest rate. This would be consistent with interest-rate policy determined by $\mathrm{CAB}$ as well as the exchange rate, similar to the German case. The D.K. data thus show influence of $C A B$ on $e$, 
Table 11: Correlations of Innovations From United Kingdom Vector Autoregression System With $M$

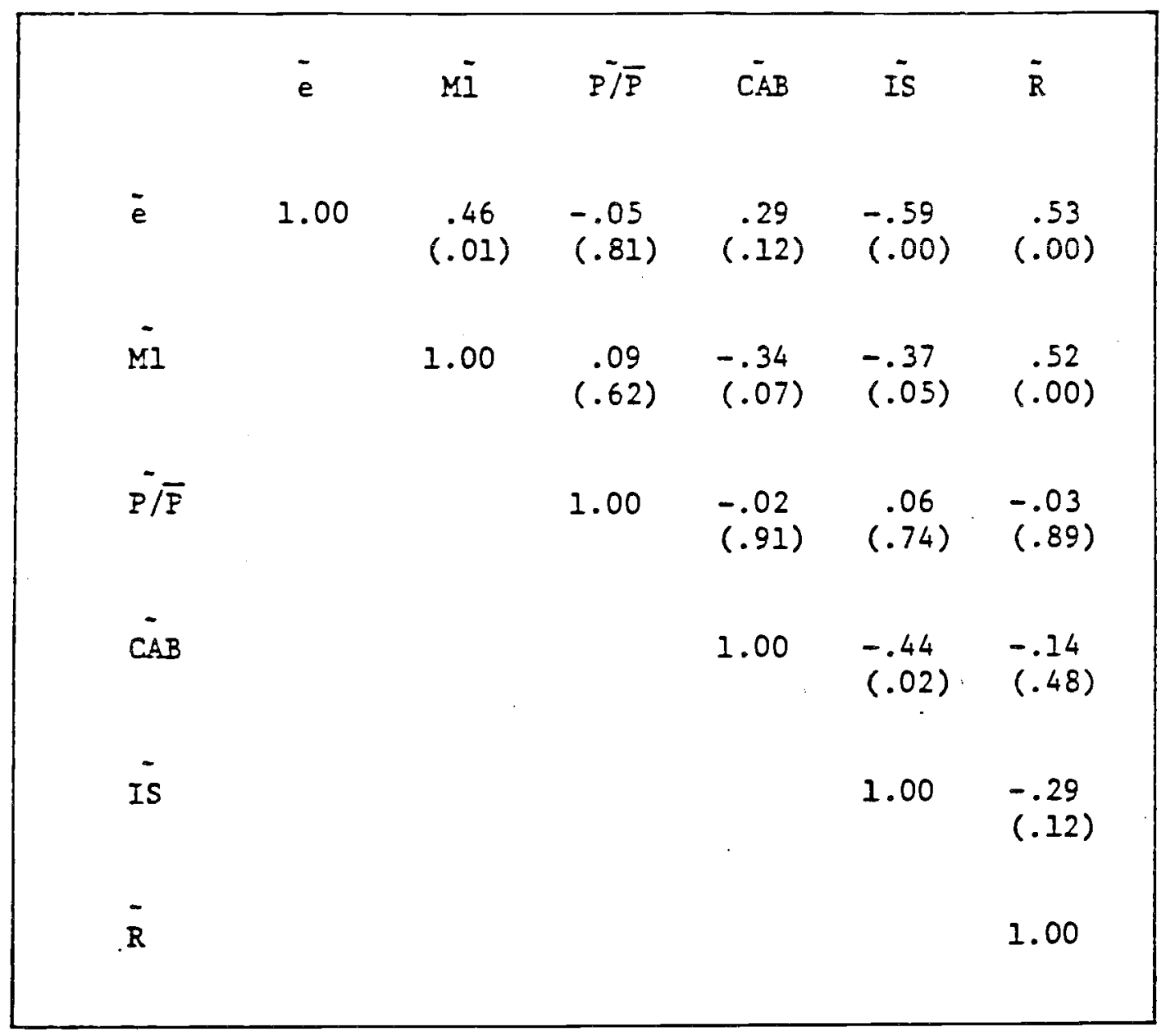


$33 b$.

Table 12: Correlations of Innovations From United Ringdom Vector Autoregression System With M3

\begin{tabular}{|c|c|c|c|c|c|c|}
\hline & $\tilde{e}$ & M3 & $\overline{P / P}$ & $\overline{C A B}$ & IS & $\mathrm{R}$ \\
\hline$\overline{\mathrm{e}}$ & 1.00 & $\begin{array}{l}-.04 \\
(.82)\end{array}$ & $\begin{array}{l}-.04 \\
(.85)\end{array}$ & $\begin{array}{l}.47 \\
(.01)\end{array}$ & $\begin{array}{l}-.55 \\
(.00)\end{array}$ & $\begin{array}{l}.44 \\
(.02)\end{array}$ \\
\hline$\overline{\mathrm{M}}$ & & 1.00 & $\begin{array}{l}.05 \\
(.79)\end{array}$ & $\begin{array}{l}.46 \\
(.01)\end{array}$ & $\begin{array}{l}-.30 \\
(.10)\end{array}$ & $\begin{array}{l}-.15 \\
(.43)\end{array}$ \\
\hline$\tilde{P} / \bar{P}$ & & & 1.00 & $\begin{array}{l}.05 \\
(.80)\end{array}$ & $\begin{array}{l}-.05 \\
(.81)\end{array}$ & $\begin{array}{l}-.04 \\
(.85)\end{array}$ \\
\hline$\overline{C A B}$ & & & & 1.00 & $\begin{array}{l}-.61 \\
(.00)\end{array}$ & $\begin{array}{l}.08 \\
(.67)\end{array}$ \\
\hline Is & & & & & 1.00 & $\begin{array}{c}-.27 \\
(.15)\end{array}$ \\
\hline$\tilde{R}$ & & & & & & 1.00 \\
\hline
\end{tabular}


with interest-rate and intervention pollcy reacting to innovations in e and $C A B$ with $M I$ unsterilized.

\section{V.E.' Japan}

The results for Japan are shown in Tables 13 and 14 . Let us focus on Table 13 first. The correlation of innovations in the exchange rate and interest rate suggest a system of interest Iate control with policy targets other than the exchange rate, rather than reaction to exchange rates as in the U.R. and Germany. The correlations of the interest rate with relative prices and the CAB suggest that these might be the targets.

The reserve correlations with the exchange rate and CAB strongly suggest "leaning-against-the-wind" intervention, with the central bark obsorbing part of the $C A B$ innovations to reduce movement in the exchange rate. The lack of correlation of $\bar{M}$ with reserves on the exchange rate indicates sterlization.

An interesting story emerges from the Japanese correlations. They suggest that policy sets interest rates with $C A B$ and $P / \bar{P}$ among the objectives. The interest rate moves the exchange rate, as in section II, and the authorities intervene to, in a sense, neutralize this effect. They also attempt to sterilize MI from all of this.

The VAR system with $M 3$ is consistent with this story in terms of signs of correlations, although significance levels vary from the MI system (in both directions - see the correlation of is and $\overline{C A B}$ ).

- V.F. Sumary of VAR Results on Policy

An interesting view of how the monetary system and interdependence have worked in the 1970 s emerges from the VAR innovation correlations. 
Table 13: Correlations of Innovations From Japan Vector Autoregression System With M

\begin{tabular}{|c|c|c|c|c|c|c|}
\hline & $\bar{e}$ & $\tilde{M I}$ & $\mathrm{P} \overline{\bar{P}}$ & $\overline{C A B}$ & IS & - \\
\hline $\bar{e}$ & 1.00 & $\begin{array}{l}-.06 \\
(.77)\end{array}$ & $\begin{array}{l}-.08 \\
(.68)\end{array}$ & $\begin{array}{l}-.03 \\
(.89)\end{array}$ & $\begin{array}{l}.55 \\
(.00)\end{array}$ & $\begin{array}{l}.33 \\
(.08)\end{array}$ \\
\hline$\dot{M I}$ & & 1.00 & $\begin{array}{l}-.10 \\
(.59)\end{array}$ & $\begin{array}{l}-.07 \\
(.71)\end{array}$ & $\begin{array}{l}-.18 \\
(.36)\end{array}$ & $\begin{array}{l}.23 \\
(.24)\end{array}$ \\
\hline $\bar{P} / \bar{P}$ & & & 1.00 & $\begin{array}{l}-.32 \\
(.09)\end{array}$ & $\begin{array}{l}.42 \\
(.02)\end{array}$ & $\begin{array}{l}-.05 \\
(.81)\end{array}$ \\
\hline$\tilde{C A B}$ & , & & & 1.00 & $\begin{array}{l}-.25 \\
(.19)\end{array}$ & $\begin{array}{l}.48 \\
(.01)\end{array}$ \\
\hline IS & & & & . & 1.00 & $\begin{array}{c}.31 \\
(.10)\end{array}$ \\
\hline $\bar{R}$ & & & & & & 1.00 \\
\hline
\end{tabular}


Table 14: Correlations of Innovations From Japan Vector Autoregression System With $M 3$

\begin{tabular}{|c|c|c|c|c|c|c|}
\hline & $\dot{e}$ & M3 & $\bar{P} / \bar{P}$ & $\overline{C A B}$ & is & $\bar{R}$ \\
\hline $\bar{e}$ & 1.00 & $\begin{array}{l}.00 \\
(.98)\end{array}$ & $\begin{array}{l}-.20 \\
(.30)\end{array}$ & $\begin{array}{l}.05 \\
(.81)\end{array}$ & $\begin{array}{l}.18 \\
(.35)\end{array}$ & $\begin{array}{l}.12 \\
(.52)\end{array}$ \\
\hline $\mathrm{M3}$ & & 1.00 & $\begin{array}{l}.02 \\
(.93)\end{array}$ & $\begin{array}{l}.12 \\
(.52)\end{array}$ & $\begin{array}{l}-.28 \\
(.14)\end{array}$ & $\begin{array}{l}.18 \\
(.34)\end{array}$ \\
\hline $\bar{P} / \bar{P}$ & & & 1.00 & $\begin{array}{l}-.36 \\
(.05)\end{array}$ & $\begin{array}{l}.43 \\
(.02)\end{array}$ & $\begin{array}{l}-.10 \\
(.61)\end{array}$ \\
\hline$\hat{C A B}$ & & & & 1.00 & $\begin{array}{l}-.60 \\
(.00)\end{array}$ & $\begin{array}{l}.33 \\
(.07)\end{array}$ \\
\hline$\dot{\text { IS }}$ & & & & & 1.00 & $\begin{array}{l}.14 \\
(.46)\end{array}$ \\
\hline $\bar{R}$ & & & & & & 1.00 \\
\hline
\end{tabular}


My interpretation, or inferred set of hypotheses is as follows. The U.S. sets monetary policy, largely by controlling quantities, with domestic objections most in wind. The market looks to innovations in money and relative prices, and levels of the current-account balance, to set the U.S. exchange rate. The monetary authority attempts sterilized intervention occasionally.

In Japan, interest rates are set with relative prices (or rates of inflation) and the current-account balance among the leading objectives. Interest-rate innovations move the exchange rate, but an attempt is made to neutralize this effect through sterilized intervention.

Movements in the U.S. and Japanese effective rates, caused partly by fundamentals and partiy by policy, are mirrored instantaneously in the U.K. and German effective rates, and their policy reacts. The reaction appears as "defensive" interest-rate movements sensitive to exchange-rate and $C A B$ innovations, and largely sterilized intervention in the foreign exchange market. Thus a consistent story in which domestically-oriented policy in the U.S. and Japan is transmitted in the U.R. and Germany is consistent with the VAR innovation results.

One final issue appears in the relations among exchange-rate and interest-rate innovations. The correlation in the U.S. is negligible, wille in the U.K. and Germany it is strongly negative. An Implication is that innovations in the dollar prices of the DM and sterling should be negatively correlated with innovations in the U.S.-German and U.S.-U.R. Interest differentials, as noted by Frenkel (1981). The 
hypothesis advanced there was that nominal interest rates and exchange rates were both reacting to changes in inflation rates. The alternative hypothesis provided here is that U.K. and German interest rate innovations are policy reactions. 


\section{FOOTNOTES}

1. Since the analysis here applies to any single country in the international financial system, I use the terms 'home' and 'foreign' to denote the country being discussed and the rest of the system, respectively. At the level of generality of this discussion no damage would be done if the reader substituted U.S. for 'home country', 'dollar' for 'home currency' and 'Fed' for 'central bank'.

2. Since $\mathrm{F}$ is home claims on foreigners less home liabilities to foreigners, an asset swap which exchanges a claim and a liability with a foreign asset-holder is a transaction within F, changing claims and liabilities by the same amount. This transaction would leave F and $B$ unchanged. The reason for using this particular aggregation will become clear when we study dynamic adjustment below. Basically, we want to define net foreign assets consistently with the balance of payments and national income and product accounts, which record the capital account balance as the change in U.S. private holdings of net foreign assets. The assumptions outlined above make $M$ and $B$ non-traded assets. This implies that the total stocks of $M, B$, and $F$ in domestic portfolios are given at any point in time.

3. The characteristic equation is given by

$$
\mathrm{P} / \overline{\mathrm{P}}_{\mathrm{t}}-1.36 \mathrm{P} / \overline{\mathrm{P}}_{\mathrm{t}-1}+0.60 \mathrm{P} / \overline{\mathrm{P}}_{\mathrm{t}-2}=0
$$

The roots of this equation are $.68 \pm .37 i$, with a modulus of $0.77=0.6^{1 / 2}$. 
4. Note that the German price equation would not invert due to multicolinearity with more than two lags.

5. A moving average specification of the equation for the U.K. CAB was also experimented with, with no improvement in results. The U.K. CAB does seem to be random about its trend.

6. The Japanese VAR results were re-estimated using a four-quarter lag on reserves, without much change. 


\section{References}

1. Amano, A., 1979, Flexible exchange rates and macroeconomic management: A study of the Japanese experience in 1973-1978. Kobe University, mimeographed.

2. Artus, J., 1976, Exchange rate stability and managed floating: the experience of the Federal Republic of Germany, International Monetary Fund Staff Papers 23, July, 312-333.

3. Ashenfelter, 0. and Card, D., 1981, Time-series representations of economic variables and alternative models of the labor market, University of Bristol, Working Paper.

4. Branson, W.H., 1975, Comment on M.v.N. Whitman: Global monetarism and the monetary approach to the balance of payments, Brookings Papers on Economic Activity 6, Number 3, 537-542.

5. Branson, W.H., 1976, Leaning against the wind as exchange rate policy, paper presented at Graduate Institute of International Studies, Geneva, revised 1981 for book publication by the Institute.

6. Branson, W.H., 1977, Asset markets and relative prices in exchange rate determination, Sozialwissenschaftliche Annalen 1, 69-89.

7. Branson, W.H., H. Halttunen and P. Masson, 1977, Exchange rates in the short run: the dollar-deutschemark rate, European Economic Review 10 December, 303-324.

8. Branson, W.H. (1980), Monetary and fiscal policy with adjustable exchange rates, in U.S. Congress, Joint Economic Committee, The International Economy: U.S. Role in a World Market, (Government Printing Office, Washington), Dec. 17, 1980, pp. 459-500. 
9. Branson, W.H. (1981), Macroeconomic determinants of real exchange rates, NBER Working Paper No. 801, November.

10. Dornbusch, R., 1980, Exchange Rate economics: where do we stand? Brookings Papers on Economic Activity II, Number 1, 143-186.

11. Fischer, S., 1981, Relative shocks, relative price variability and inflation, Brookings Papers on Economic Activity 12, Number 2, forthcoming.

12. Frenkel, J., 1981b, Flexible exchange rates, prices and the role of "news": Lessons from the 1970's, Journal of Political Economy 89, August, $665-705$.

13. Herring, R.J. and R.C. Marston (1977), National Monetary Policies and International Financial Markets, (North-Holland, Amsterdam).

14. Kenen, P.B. (1982), Effects of intervention and sterilization in the short run and the long run, in R.N. Cooper, P.B. Kenen, J.B. de Macedo, J. van Ypersele (eds), The International Monetary System under Flexible Exchange Rates: Essays in honor of Robert Triffin, (Ballinger, Cambridge MA, 1982), pp. 51-68.

15. Kouri, P.J.K., (1978), Balance of payments and the foreign exchange market: a dynamic partial equilibrium model, Yale University, Cowles Foundation Discussion Paper No. 510.

16. Mussa, M. (1981), The Role of Official Intervention, Occasional Paper 6, New York, Group of 30 .

17. Obstfeld, M., 1980, Portfolio balance, monetary policy, and the Dollar-Deutschemark exchange rate, Columbia University Economics Dept., Discussion Paper No. 62, March 1982. 
18. Obstfeld, M., 1982, Can we sterilize? Theory and evidence, forthcoming American Economic Review, May 1982.

19. OECD Interfutures (1977), Long term aspects of the monetary system, mimeo, OECD Paris, September 30, 1977.

20. Sargent, T., 1979, Estimating vector autoregressions using methods not based on explicit economic theories, Federal Reserve Bank of Minneapolis Quarterly Review, Summer, 8-15.

21. Sims, C., 1980, Macroeconomics and reality, Econometrica 48, January, 1-48.

22. Taylor, J., 1980, Output and price stability: an international comparison, Journal of Economic Dynamics and Control 2, February, 109-132.

23. Whitman, M.v.N. (1975), Global monetarism and the monetary approach to the balance of payments, Brookings Paper on Economic Activity, $3: 1975$, pp. 471-536. 